\section{Perfil epidemiológico dos casos de coqueluche no Brasil nos anos de 2010 a 2014*}

\section{Epidemiological profile of pertussis cases in Brazil in the years 2010-2014}

Hannah Waleska Viegas de Castro $^{1}$ Bruno Silva Milagres ${ }^{2}$
* Recebido em: 17/07/2016. Aprovado em: 04/10/2017.

1 Estudante de Biomedicina do Centro Universitário de Brasília - UniCEUB. E-mail: hannah. waleska@gmail.com.

2 Professor Doutor do Centro Universitário de Brasília - UniCEUB. E-mail: bruno.milagres@ uniceub.br.

\section{Resumo}

A coqueluche é uma doença infecciosa aguda de notificação compulsória causada pela bactéria Bordetella pertussis. Ela acomete o trato respiratório e seu principal sintoma é a tosse paroxística. Essa acomete todas as idades, mas é mais frequente e grave em menores de 1 ano. O objetivo deste trabalho é apresentar a epidemiologia descritiva e a cobertura vacinal no Brasil nos anos de 2010 a 2014, sendo realizado por meio de revisão bibliográfica no contexto epidemiológico apresentando os dados de tempo, pessoa e lugar. A cobertura vacinal atingiu o preconizado em todos os anos, entretanto, este não ocorreu de forma homogênea. Houve um aumento de $1.505 \%$ de casos do ano de 2010 a 2014, configurando uma possível reemergência da doença. A causa desse aumento ainda não foi elucidada, porém, há hipóteses que relacionam com a melhora diagnóstica, vigilância epidemiológica mais sensível, uma cepa mais virulenta e a redução da imunização após alguns anos da última dose da vacina.

Palavras-chave: Coqueluche. Bordetella pertussis. Epidemiologia. Vigilância epidemiológica. Vacina.

\begin{abstract}
Whooping cough is an acute infectious disease of compulsory notification caused by the bacterium Bordetella pertussis. It affects the respiratory tract and its main symptom paroxysmal cough. This disease affects all ages, but is more frequent and severe in children under 1 year. The objective of this article is to present the descriptive epidemiology and the vaccine coverage in Brazil in the years 2010-2014, that was performed through literature review in the epidemiological context presenting the data about time, person and place. Its vaccination coverage reached the recommended in every year, however this did not occur homogeneously. There was an increase of $1,505 \%$ on cases from the year 2010 to 2014, setting up a possible reemergence of the disease. The cause of this increase has not yet been elucidated, but there are cases that relate to the diagnosis improves, more sensitive surveillance, virulent strain, and the reduction of immunization some years after the last dose of vaccine.
\end{abstract}

Keywords: Whooping cough. Bordetella pertussis. Epidemiology. Epidemiologic surveillance. Vaccine. 


\section{Introdução}

A coqueluche, acarretada pela bactéria Bordetella pertussis (B. pertussis), também conhecida por "tosse comprida", é uma enfermidade infecciosa aguda, altamente contagiosa que acomete o trato respiratório humano, principalmente os brônquios e a traqueia (MATTOO; CHERRY, 2005).

A B. pertussis é uma bactéria da família Alcaligenaceae, sendo um cocobacilo gram-negativo extremamente pequeno, não fermentador, não esporulado, imóvel, com fímbrias e totalmente dependente do oxigênio, sendo aeróbio obrigatório. As bactérias que possuem a linhagem virulenta secretam toxinas que formam uma cápsula que favorecerá a adesão da bactéria às células ciliadas da traqueia impedindo a sua ação e, posteriormente, destruindo suas células (TORTORA; FUNKE; CASE, 2012)

Sua transmissão ocorre a partir do contado direto com a pessoa infectada, por meio de gotículas da orofaringe que podem ser eliminadas por espirro, ao falar ou ao tossir. A transmissão por contato indireto, fazendo uso de material contaminado, é incomum, devido ao agente não sobreviver fora do hospedeiro, sendo o homem o único reservatório natural até o momento. $\mathrm{O}$ período de incubação da doença é, em média, de cinco a dez dias (BRASIL, 2015a).

A coqueluche possui um período médio de duração de 6 a 12 semanas podendo se estender por mais tempo, sendo dividida em três fases (catarral, paroxística e convalescença) conforme sinais e sintomas. A primeira fase, catarral, tem duração de 7 a 14 dias e é caracterizada por conter sintomas comuns ao do resfriado, podendo apresentar tosse leve, rinorreia e temperatura normal ou levemente aumentada à medida que há o avanço da doença, ressalta-se que essa fase é a de maior transmissibilidade. Já na segunda fase, paroxística, tem duração de 2 a 8 semanas e seus sintomas tornam-se mais acentuados, tendo acessos mais frequentes e intensos de tosse, guinchos respiratórios, vômitos pós-tosse e cianose (MATTOO; CHERRY, 2005; TOZZI et al., 2005).

A fase de convalescença, terceira fase, tem duração média de uma a duas semanas, podendo durar meses conforme a pessoa acometida, por exemplo, lactentes jovens ( $<6$ meses); essa ocorre de forma gradual com a diminuição dos paroxismos e uma melhora no quadro geral do paciente. No entanto, durante as fases, principalmente na fase paroxística, podem ocorrer complicações como pneumonia, otite média, convulsões e encefalopatia, sendo as duas últimas devido a uma hipóxia cerebral relacionada aos paroxismos graves, complicando a recuperação total do paciente podendo levar ao óbito (BRASIL, 2015a; MATTOO; CHERRY, 2005; TOZZI et al., 2005).

No Brasil, o exame laboratorial mais utilizado para o diagnóstico da Coqueluche é a cultura de secreção da nasofaringe com o isolamento da bactéria B. pertussis, sendo essa técnica considerada teste de referência por sua alta especificidade. Além deste existem outros que ainda não foram implantados na rotina laboratorial, mas auxiliam no momento do diagnóstico, como: imunofluorescência, sorologia, reação em cadeia de polimerase (PCR) e PCR em tempo real (RT-PCR) (BRASIL, 2001; BRASIL, 2009).

Com relação ao tratamento, a coqueluche tinha como antibiótico preferencial até 2005 a eritromicina, que é bastante eficaz na eliminação da B. pertussis da nasofaringe em um ou dois dias. $\mathrm{O}$ tratamento é prolongado (7 a 14 dias), o que gera uma rejeição por parte dos enfermos por seus efeitos colaterais e, também, por ser contraindicada para menores de um mês de vida (KONEMAN, 2012; PASTOR, 2001).

Com o advento de novos antibióticos, percebeu-se que a azitromicina e a claritomicina possuem a mesma eficácia para o tratamento e quimioprofilaxia da coqueluche, sendo administradas no intervalo de 5 e 7 dias, respectivamente. Essa forma de uso dos antibióticos facilitou a adesão dos pacientes ao tratamento, a quimiprofilaxia dos contatos próximos ao enfermo e também pela permissão do uso da azitromicina em crianças com menos de um mês de idade. Caso haja alguma contraindicação avaliada pelo médico ou o paciente seja intolerante aos antibióticos da classe dos macrolídeos, é indicado o uso de sulfametoxazol-trimetoprin (SMZ-TMP). Dessa forma, o esquema de tratamento para a coqueluche segue a ordem de escolha: azitrocimicina, claritromicina, eritromicina e SMZ-TMP (BRASIL, 2014c; LONGO, 2013).

A coqueluche é uma enfermidade de notificação compulsória e vem sendo considerada reemergente no Brasil, Estados Unidos, Austrália e em diversos países da Europa, infectando todas as faixas etárias, por estar apresentando mais casos do que o observado entre os anos de 1990 a 2010. Estudos epidemiológicos têm destacado que, na Califórnia (EUA), no ano de 2010, houve o registro de 9.146 casos com dez óbitos de crianças menores de 
seis meses de idade. No mesmo ano, a Europa registrou 15.749 casos, dos quais acometeram, principalmente, a Holanda e a Noruega. Já na Austrália foram registrados 35 mil casos de coqueluche entre julho de 2010 a julho de 2011. Os motivos que levaram a esse aumento do número de casos a partir de 2010 ainda estão sendo analisados por todas as localidades acometidas (BRASIL, 2011).

A partir dessa pré-análise, o estudo tem como objetivo apresentar a epidemiologia descritiva em tempo, pessoa e lugar, e a cobertura vacinal da Coqueluche no Brasil nos anos de 2010 a 2014.

\section{Metodologia}

O presente trabalho refere-se a um estudo descritivo no contexto epidemiológico, em que serão utilizados os dados existentes na base de dados Sistema de Informação de Agravos de Notificação (SINAN) e Sistema de Informação do Programa Nacional de Imunizações (SI-PNI).

O levantamento dos artigos foi realizado por meio de pesquisa nas bases bibliográficas EBSCO, PUBMED, Scielo, Bireme, no Portal de Teses da USP, em livros acadêmicos disponibilizados na biblioteca do UniCEUB e em documentos relacionados no site do Ministério da Saúde e da Organização Mundial da Saúde (OMS). As palavras-chave para esta pesquisa foram: Coqueluche, Bordetella pertussis, epidemiologia, vigilância epidemiológica, vacina, sendo estas utilizadas tanto em português como em inglês. As palavras-chave foram utilizadas, separadamente, e aos pares com o auxílio do conector "AND”.

O intervalo de tempo definido para a busca foi de trabalhos publicados nos últimos 15 anos e que tenham as palavras-chave apresentadas acima.

\section{Desenvolvimento}

Figura 1 - Série histórica dos casos confirmados de coqueluche no Brasil do ano de 2004 a 2014

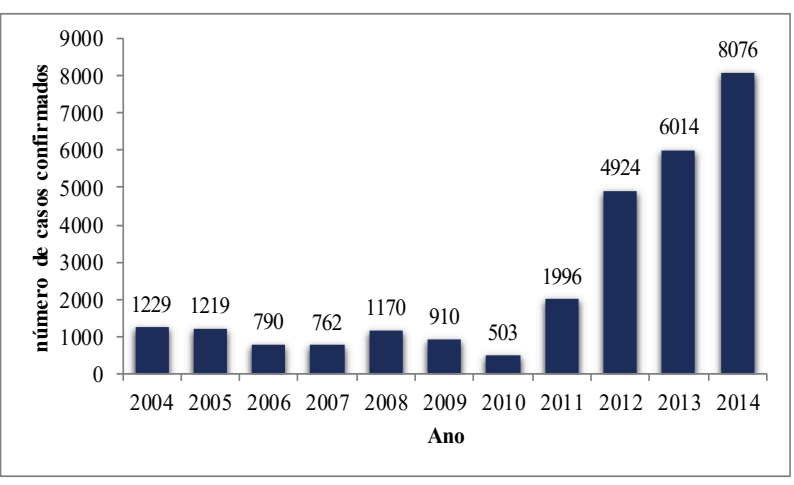

Fonte: BRASIL, 2015c.
Em todo o mundo, principalmente no Brasil, EUA e Europa, houve um aumento significativo do número de casos de coqueluche a partir do segundo semestre de 2010. Esse aumento é bastante evidente nos anos subsequentes, já que o ano de 2011 apresentou um aumento de $367 \%$ comparado ao total de casos confirmados no ano de 2010 (Figura 1) (BRASIL, 2011).

O Ministério da Saúde ainda investiga a elevação súbita de casos que ocorreram a partir do ano de 2010, como mostrado na figura 1. A hipótese para o aumento de casos da coqueluche é uma maior sensibilidade por parte da vigilância laboratorial, devido à introdução de técnicas biomoleculares na rotina laboratorial que torna o diagnóstico mais rápido, sensível e preciso (BRASIL, 2011).

Outra consideração é a vacinação das gestantes, pois o descomprometimento com o calendário de vacina gestacional deixa os bebês desprotegidos por estes não receberem a imunização natural passiva por via placentária e pelo aleitamento materno. Uma última consideração é do desrespeito ao calendário vacinal da criança por parte dos pais, não levando seus filhos aos postos de vacinação para receber todas as doses necessárias para uma completa imunização (BRASIL, 2014d).

$\mathrm{Na}$ figura 2, pode-se observar o número de casos por meses dos anos de 2011 a 2014, esse não apresenta os dados do ano de 2010 pelo fato de não estar disponibilizado pelo Mistério da Saúde.

Figura 2 - Número total de casos por mês entre os anos de 2011 a 2014.

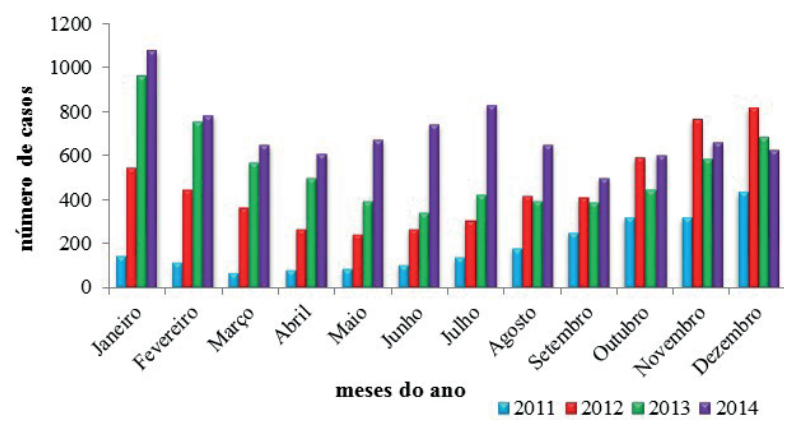

Fonte: BRASIL, $2015 \mathrm{C}$

Verificam-se, no gráfico acima, uma sazonalidade da doença na primavera e no verão (setembro a março) e um pico no mês de julho quando ocorre o inverno mais intenso. Esses dados sugerem que a sazonalidade da doença ocorre em razão do aumento da temperatura que ocorre nesses meses, favorecendo o metabolismo da bactéria que possui temperatura ótima entre $25^{\circ}$ e $35^{\circ} \mathrm{C}$. Já o 
pico no mês de julho ocorre em virtude da maior aglomeração de pessoas devido ao tempo mais frio, favorecendo a transmissão da bactéria devido ao aumento do contato pessoa-pessoa (ULLOA, 2008).

Durante o ano de 2011, houve um aumento crescente do número de casos, com início no mês de setembro perdurando até o mês de março de 2012, seguindo a sazonalidade da enfermidade, como citado em BRASIL (2011), confirmando o aumento do número de casos a partir desse ano (Figura 2).

Seguindo o fator temperatura e pessoa, a figura 3 expõe o número de casos por região do Brasil, sendo possível fazer uma análise relacionada ao contingente populacional de cada região do país.

Figura 3 - Número total de casos notificados por região entre os anos de 2010 a 2014

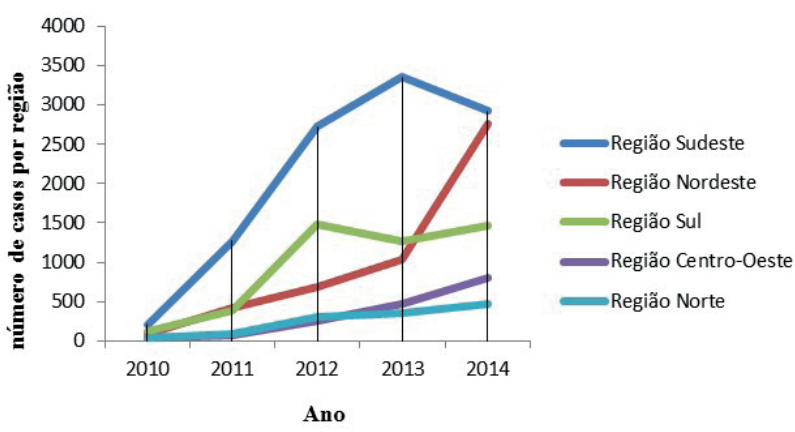

Fonte: BRASIL, 2015c

A partir da análise da figura 3, é possível concluir que há maior número de casos na região Sudeste, seguido das regiões Nordeste e Sul, com uma menor quantidade de casos nas regiões Norte e Centro-Oeste. O maior número de casos segue o padrão populacional de cada região, sendo o Sudeste a região mais populosa do país com mais de 70 milhões de habitantes e a região Centro-Oeste com um pouco mais de 11 milhões de habitantes (BRASIL, 2016a).

Além do fator populacional, é possível analisar o número de casos correlacionando com o tempo, o clima e área territorial. A região Sudeste possui o maior número populacional do país, com um predomínio de clima tropical e com temperaturas que variam de acordo com a estação do ano, mas, durante o verão e primavera, quando ocorre o maior número de casos, possui temperatura por volta dos $30^{\circ} \mathrm{C}$, favorecendo o metabolismo da bactéria. Já de acordo com a extensão territorial, é notório que a maior população do país se encontra em uma região com uma área territorial menor, o que colabora para a transmissão da doença devido ao maior aglomeração de pessoas (BRASIL, 2016c; ULLOA, 2008).

Já a região Nordeste possui uma climática complexa que envolve o clima equatorial, tropical, litorâneo e tropical semiárido, mas no geral possui um clima úmido, com temperaturas elevadas, é a $3^{\text {a }}$ maior região do país e possui uma rotatividade muito grande devido ao seu turismo. Em contrapartida, a região Sul do país é a menor em extensão territorial, com predomínio do clima subtropical responsável pelas baixas temperaturas na região. Entretanto, no período de maior transmissibilidade da coqueluche, as temperaturas podem variar entre $28^{\circ}$ e $32^{\circ} \mathrm{C}$, o que favorece a propagação da bactéria (BRASIL, 2016d).

Por fim, a região Norte possui um clima equatorial que se caracteriza por ser quente e por possuir temperaturas variando entre os $24^{\circ}$ e $26^{\circ} \mathrm{C}$. É a maior região do país e possui uma população bem distribuída, o que contribui para um menor contato direto entre as pessoas, reduzindo as chances de contaminação da enfermidade. E a região Centro-Oeste, segunda maior área territorial do Brasil, é caracterizada por possuir um clima tropical semiúmido e temperaturas elevadas durante o verão e primavera favorecendo a propagação da bactéria (BRASIL, 2016d; BRASIL, 2016c).

Para uma melhor análise da diferença do número de casos entre os anos de 2010 e 2014 e para observar a influência do clima, temperatura e extensão territorial, observa-se a conforme apresentado na Figura 4.

Figura 4 - Comparativo do número de casos de coqueluche por Unidade Federativa do Brasil nos anos de 2010 e 2014.

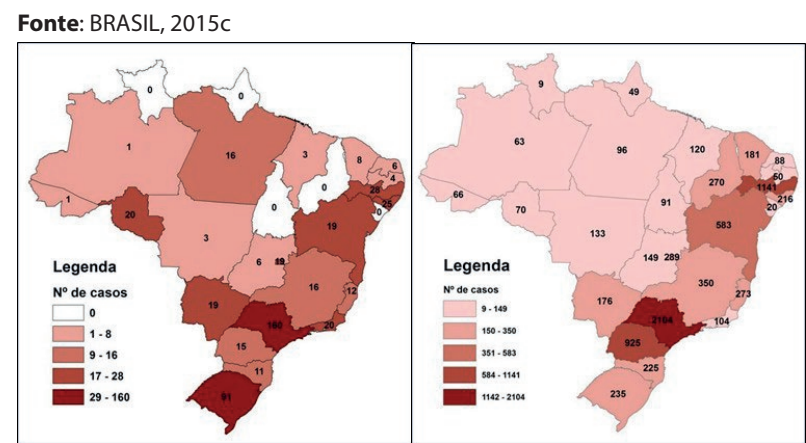

Com base na Figura 4, é possível observar o crescente aumento no número de casos de um ano para o outro, em que em 2010 havia quatro estados brasileiros sem registro de casos e, no ano de 2014, todos os estados registraram casos da doença. Ao todo foram registrados 503 casos de Coqueluche em 2010 e 8076 casos em 2014, o que representa um aumento de $1.505 \%$ do ano de 2010 
para o ano de 2014. Como dito anteriormente, ainda não há uma causa definida para esse aumento, mas estudos sugerem que houve, principalmente, a introdução do teste biomolecular, que melhora o diagnóstico, e mudanças nas características antigênicas da $B$. pertussis (BRASIL, 2014d; BRASIL; 2015c).

Para a análise epidemiológica sob a variável pessoa, observa-se a figura 5 a qual apresenta o número de casos que acometem o sexo feminino e masculino.

Figura 5 - Número de casos notificados de coqueluche por sexo nos anos de 2010 a 2014.

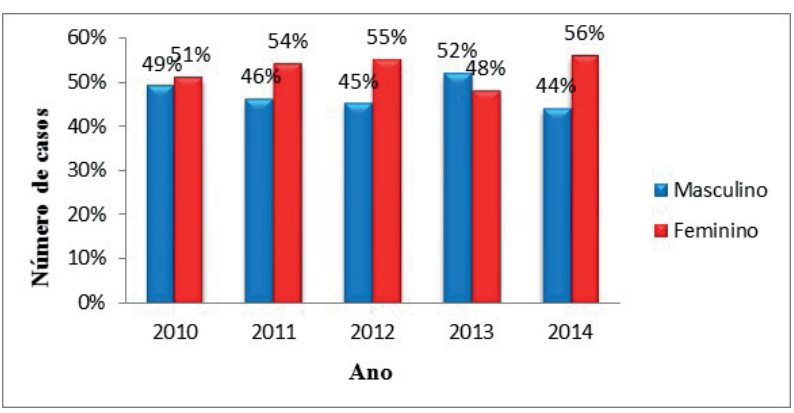

Fonte: BRASIL, 2015c

A partir da análise da figura 5 pode-se afirmar que a bactéria B.pertussis não possui predileção por sexo. A diferença do número de casos apresentada no gráfico é pequena e esperada devido ao processo de notificação da doença (BRASIL, 2011).

Alguns estudos sugerem que essa pequena diferença de notificação ocorre devido a maior vigilância da Coqueluche em mulheres principalmente durante o período gestacional por estas poderem transmitir a doença para os bebês, aumentando os casos de Coqueluche em recém-nascidos (PINTO, 2007).

Sob a perspectiva da incidência em crianças, a figura 6 mostra o número de casos notificados de acordo com a idade da população, sendo possível correlacionar o elevado número de casos em crianças com o número de casos que acometeram as gestantes no mesmo período (Figura 7).

Figura 6 - Número de casos notificados por idade entre os anos de 2010 a 2014.

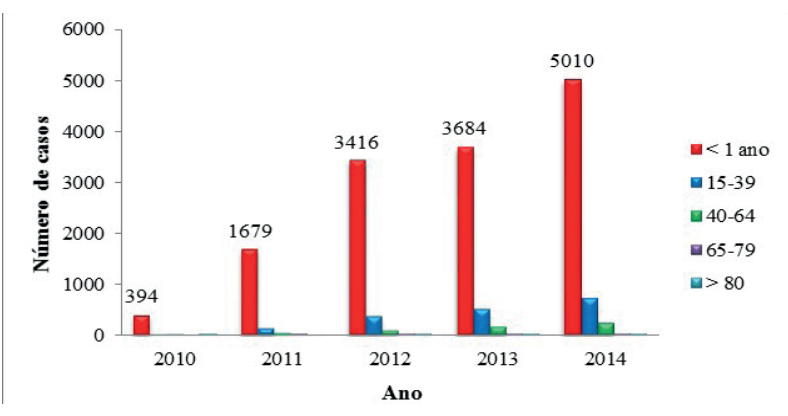

Fonte: BRASIL, 2015c
$\mathrm{Na}$ figura 6, observa-se que há maior incidência da enfermidade em crianças menores de 1 ano de idade, seguido pela faixa etária dos 15-39 anos e alguns casos em idosos. Embora haja baixo número de casos nos idosos mostra-se uma preocupação devido à imunização não conferir imunidade em longo prazo, reduzindo a imunidade em adultos e idosos que podem desenvolver uma forma mais leve da doença de forma assintomática se tornando fonte de infecção para crianças, gestantes e pessoas não imunizadas (WILLEMANN, 2014).

A partir dessa análise, observa-se um maior número de casos em lactentes, principalmente em menores de seis meses. Em virtude de estes, ainda, não terem recebido todo o esquema de imunização que é administrado a partir dos dois meses. Outro fator se apresenta em virtude de as gestantes não terem sido imunizadas com a vacina dTpa durante a gestação, não transferindo imunidade para o bebê e, também, porque a criança entra em contato com adultos que podem estar infectados de forma assintomática e acabar por infectar a criança. Dessa forma, por observar a elevada taxa de incidência em lactentes, iniciou-se a discussão para criar uma nova estratégia de vacinação contra a coqueluche, incluindo, em 2014, no calendário de vacina a Tríplice Acelular (dTpa) para gestantes da $27^{\mathrm{a}}$ a $36^{\mathrm{a}}$ semana de gestação (BRASIL, 2014e; TORRES, 2015).

Figura 7 - Número de casos de coqueluche em gestantes no período de 2010 a 2014.

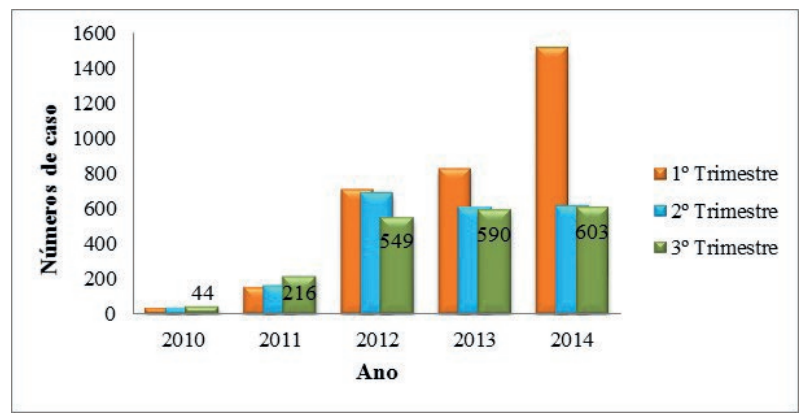

Fonte: BRASIL, 2015c.

A partir da figura 6, conclui-se que há maior incidência de casos de coqueluche no primeiro trimestre da gestação. Esse aumento é em virtude da vacina dTpa ser aplicada apenas a partir do sétimo mês de gestação ( $3^{\circ}$ trimestre), como preconiza o calendário de vacinação do Ministério da Saúde. Dessa forma, a gestante não confere imunidade nos trimestres anteriores (BRASIL, 2014b; BRASIL, 2014d).

Ao realizar um comparativo com o número de casos em gestantes com as crianças menores de um ano, é 
possível analisar que, após o início da aplicação da vacina dTpa nas gestantes, houve redução de casos tanto nas gestantes quanto nos lactentes. Como pode ser observado a partir de uma pré-análise dos dados referentes ao ano de 2015, em que há 1581 casos em crianças com até 1 ano e 167 casos em gestantes durante o $3^{\circ}$ trimestre da gestação, possuindo uma redução do número de casos de aproximadamente $68 \%$ e $72 \%$, respectivamente (BRASIL, 2015b).

Com o intuito de analisar as zonas mais acometidas pela enfermidade, a figura 8 expõe o número de casos que compreendem a zona rural e urbana, mostrando a defasagem no sistema de notificação da zona rural.

Figura 8 - Casos notificados por zona de contágio nos anos de 2010 a 2014.

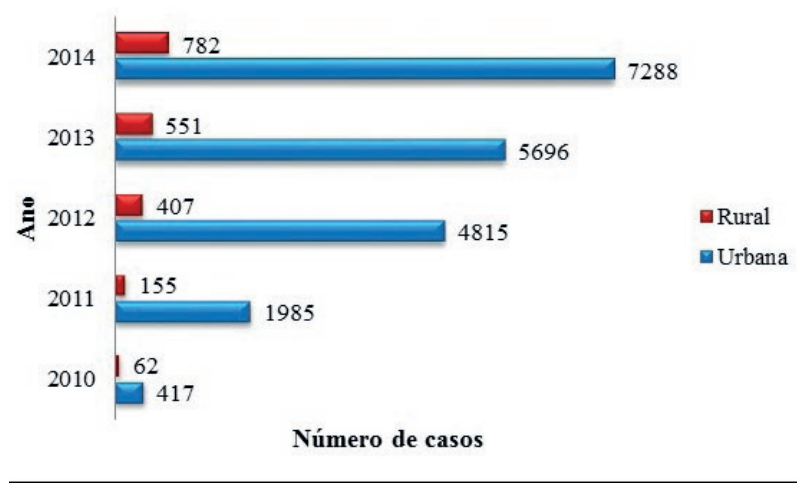

Fonte: BRASIL, $2015 \mathrm{C}$

Seguindo os dados apresentados no gráfico acima, atenta-se para a diferença de casos notificados entre as regiões. Essa desproporção ocorre em virtude de o $\mathrm{Mi}$ nistério da Saúde possuir um maior controle de notificação na área urbana por consequência da população rural não procurar os postos de saúde quando apresentam os sintomas da doença, realizando tratamento com métodos caseiros sem obter um diagnóstico para a causa de seus sintomas e, ainda, devido ao difícil acesso da população aos postos de saúde nas regiões mais remotas do país (KASSOUF, 2005; BARBOSA, 2010; VIEIRA, 2010).

A figura 9 apresenta os métodos para a confirmação diagnóstica da coqueluche, sendo estes o laboratorial e o clinico epidemiológico.
Figura 9 - Confirmação diagnóstica para os casos confirmados no período de 2010 a 2014

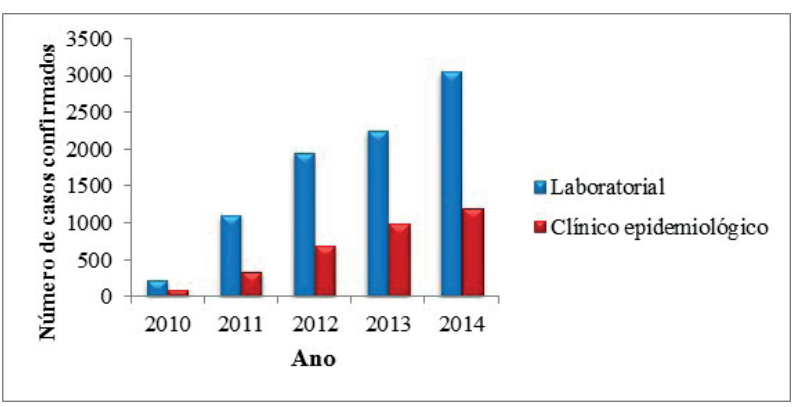

Fonte: BRASIL, 2015c.

A figura 9 apresenta o método diagnóstico utilizado para confirmar os casos de coqueluche. Para ser realizado o diagnóstico clínico epidemiológico, é necessário que o indivíduo atenda aos critérios de caso suspeito e tenha tido contato com algum caso confirmado ou tenha visitado um local com alta incidência de coqueluche. Já para a efetuação do diagnóstico laboratorial, é necessário, apenas, que a pessoa com suspeita e com sinais e sintomas da doença procure um serviço de saúde e realize o exame diagnóstico (TORRES, 2015).

A suspeita para a realização do diagnostico ocorre a partir do quadro clínico, que deve ser compatível com os sinais e sintomas da doença. Sendo assim, será considerada, para efeito de diagnóstico no Brasil, toda pessoa sem outra causa aparente que apresente tosse seca por, pelo menos, duas semanas, acompanhada de tosse paroxística e/ou guincho inspiratório e/ou vômito pós-tosse (BRASIL, 2010; CVE, 2001).

Para um melhor diagnóstico laboratorial por meio do isolamento da bactéria, é importante que este seja realizado nas semanas iniciais dos sintomas e antes de serem administrados antibioterápicos. O isolamento da bactéria B. pertussis é a técnica "padrão-ouro" para o diagnóstico da enfermidade. Além desse método diagnóstico, iniciou-se a utilização de testes biomoleculares que possuem maior especificidade e sensibilidade, aumentando a confirmação diagnóstica da coqueluche (BRASIL, 2001; BRASIL, 2009).

Diante dos registros apresentados, a figura 10 mostra o desfecho da doença com o número de casos que foram à cura ou levaram ao óbito, com ênfase na quantidade de óbitos causados pela coqueluche nos anos em análise. 


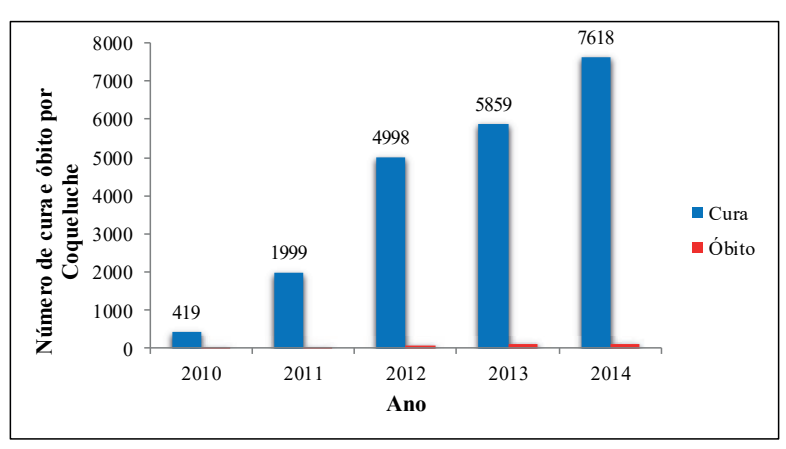

Figura 10 - Registro do número de cura e óbitos entre os anos de 2010 a 2014.

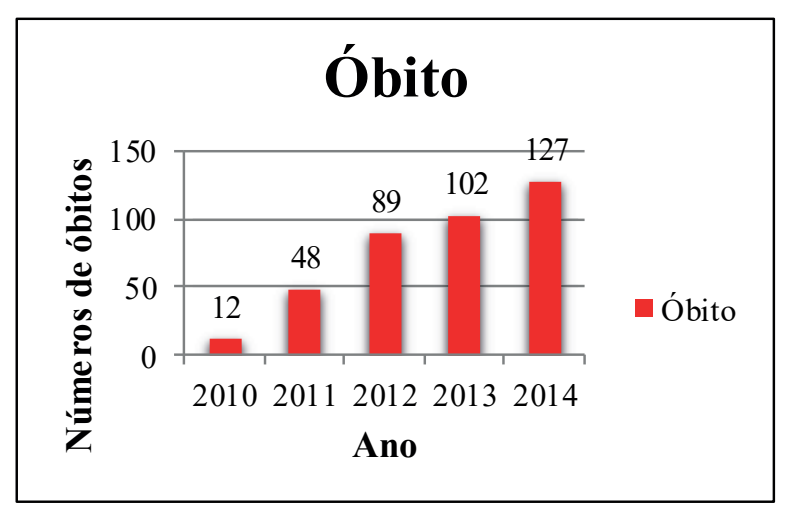

Fonte: BRASIL, 2015c

Grande parte dos casos de coqueluche possui uma boa resposta terapêutica e progridem para a cura. O tratamento realizado nos pacientes ocorre por meio da ministração de antibióticos (Azitrocimicina, Claritromicina, Eritromicina e SMZ-TMP) que são eficazes para a eliminação da bactéria da nasofaringe dos pacientes. Com o advento dos novos antibióticos, houve um aumento significativo de casos curados. Por consequência, obtém-se uma melhor resposta ao tratamento e, também, melhor resposta aos resultados profiláticos da doença (BRASIL, 2014c; LONGO, 2013).

No entanto, mesmo com o aumento do aceite para a realização da terapia e o aumento de pessoas que tiveram contado com a bactéria para a realização da quimioprofilaxia, a quantidade de óbitos segue o aumento do número de casos a partir do segundo semestre de 2010. Em relação aos 378 óbitos de 2010 a 2014, 374 ocorreram em crianças menores de 1 ano de idade, confirmando que estas são as mais gravemente acometidas pelo agravo devido ao seu fraco sistema imunológico e, ainda, por não terem o esquema completo de vacinação (BRASIL, 2015c; MOTTA; CUNHA, 2012).

No quadro 1 é possível observar a taxa de mortalidade, morbidade e letalidade da coqueluche no Brasil em todas as faixas etárias em que será possível realizar uma análise mais completa do comprometimento que essa doença pode levar à população.

Quadro 1: Morbidade, mortalidade e letalidade dos casos de coqueluche registrados no Brasil de 2010 a 2014.

\begin{tabular}{|c|c|c|c|}
\hline Ano & Morbidade & Mortalidade & Letalidade \\
\hline 2010 & $2,5 \times 10^{-3}$ & $6,1 \times 10^{-5}$ & 2,38 \\
\hline 2011 & $1 \times 10^{-2}$ & $2,7 \times 10^{-4}$ & 2,75 \\
\hline 2012 & $2,4 \times 10^{-2}$ & $4,2 \times 10^{-4}$ & 1,72 \\
\hline 2013 & $3 \times 10^{-2}$ & $5,4 \times 10^{-4}$ & 1,82 \\
\hline 2014 & $3,9 \times 10^{-2}$ & $5,9 \times 10^{-4}$ & 1,51 \\
\hline
\end{tabular}

Fonte: BRASIL, 2015c.

A partir do quadro 1, é possível confirmar o aumento no número de casos e óbitos pelo agravo a partir de 2010. Esse aumento é melhor observado realizando-se a comparação entre os anos de 2010 e 2014, em que os números referentes à morbidade e à mortalidade da doença aumentaram de um ano para o outro. Entretanto, quando se observa o parâmetro letalidade, nota-se que houve uma redução do ano de 2010 para o ano de 2014, isto se dá devido ao aumento do número de óbitos não ser proporcional ao aumento do número de casos confirmados, levando, assim, a uma diminuição da letalidade da doença (BRASIL, 2009; MOTTA, 2012).

Ainda a respeito da letalidade da coqueluche, é possível realizar um comparativo entre a letalidade total dos casos e a letalidade entre os menores de 1 ano de idade que possuem um valor de 2,59 no ano de 2014. Dessa forma, observa-se que a letalidade é maior em lactentes, superando o valor que engloba todas as faixas etárias, como visto no quadro acima (BRASIL, 2015c; TORRES, 2015).

A fim de associar o aumento do número de casos a uma causa específica, a figura 11 evidencia a cobertura vacinal da coqueluche de 1990 a 2014, tendo em foco, apenas, os anos de 2010 a 2014.

Figura 11 - Cobertura vacinal da coqueluche nos anos de 2010 a 2014

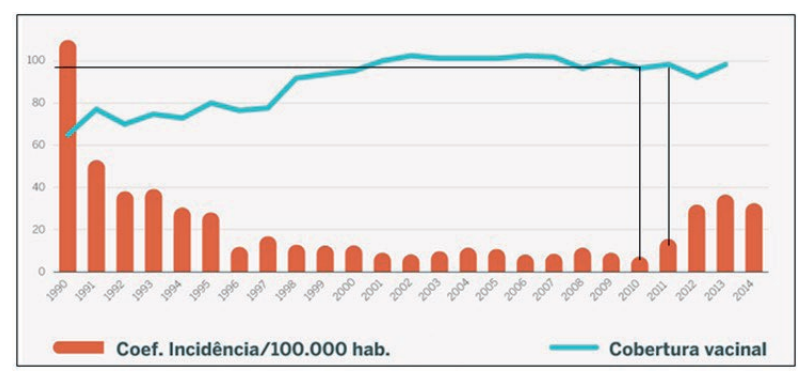

Fonte: SBIM, 2016 
Em 1973, no Brasil, foi criado o Plano Nacional de Imunização (PNI) com o objetivo de promover a imunização com vacinas de qualidade e que sejam distribuídas de forma homogênea por todas as regiões, municípios e bairros do país. A partir desse programa, foi possível uniformizar o calendário de vacinação para que atinja as crianças, adolescentes, adultos, idosos e gestantes. Dessa forma, como meio de profilaxia para a coqueluche, implantou-se a vacina pentavalente que oferece proteção contra a difteria, tétano, coqueluche, hepatite B e doenças invasivas causadas por Haemophilus influenzae do tipo B (BRASIL, 2014a; BRASIL, 2014b; BRASIL, 2015b).

A figura 10 retrata a situação vacinal contra a coqueluche, demonstrando que, desde o ano de 2007, a cobertura vacinal está acima de $80 \%$ como preconiza o Ministério da Saúde. Essa cobertura permanece alta até o ano de 2014, mas, como mostra o gráfico, houve uma pequena queda no ano de 2010 que permaneceu acima do preconizado e não pode ser considerada a causa do aumento do número de casos a partir desse ano. Entretanto, a vacina dTpa, para gestantes só foi inserida no PNI em 2014, o que sugere o aumento de casos em crianças menores de 1 ano nos anos anteriores, em virtude de estas, ainda, não terem recebido a imunização completa oferecida pela vacina (BRASIL, 2016e).

O Ministério da Saúde preconiza três doses de vacinação, com intervalo de 60 dias, a partir dos dois meses de idade. Portanto, ministra-se a vacina pentavalente aos 2, 4 e 6 meses, e realizam-se dois reforços aos 15 meses e aos 4 anos de idade com a vacina tríplice bacteriana (DTP). Somente a partir de 2014, foi implantado, no calendário de vacina, a Tríplice Acelular (dTpa) para gestantes da $27^{\mathrm{a}}$ a $36^{\mathrm{a}}$ semana de gestação a fim de diminuir os casos da enfermidade em crianças por transferir imunidade a essas nos primeiros meses de vida. Caso ocorra a diminuição da disponibilidade dessa vacina, é possível que ocorra um aumento da morbidade da doença, entretanto, isso não influenciará a letalidade desta, em virtude de os adultos possuírem o sistema imune mais forte e ter um bom prognóstico da doença (BRASIL, 2014a; BRASIL, 2014c).

O Ministério da Saúde, ainda, não disponibilizou todos os dados epidemiológicos referentes ao ano de 2015. Os dados divulgados até o momento podem sofrer revisão. A fim de ilustrar um parâmetro mais recente dos casos de coqueluche no Brasil, será descrito abaixo os dados divul-
O número de casos registrados até o início do mês de outubro (40 a semana) foi de 2.536 casos confirmados. Sendo esses distribuídos, em ordem crescente, entre as regiões Sudeste, Nordeste, Sul, Centro-Oeste e Norte. A idade mais acometida segue o mesmo padrão, sendo 1.581 casos confirmados em crianças menores de 1 ano e 533 casos no $1^{\circ}$ trimestre de gestação. Já com relação aos óbitos, verificaram-se 27 pelo agravo e 2.237 casos que progrediram para a cura (BRASIL, 2015c).

\section{Considerações Finais}

Conclui-se que o aumento de casos a partir de 2010 não é devido à falha do sistema de vacinação, embora, atualmente, a rede pública de saúde esteja com falta da vacina dTpa para gestantes, configurando um maior risco para os menores de 1 ano. A meta proposta pelo Ministério da Saúde para a cobertura vacinal no país foi alcançada, entretanto, essa cobertura não possui uma homogeneidade dos vacinados por UF, o que caracteriza o aumento de casos.

A partir do estudo, serão consideradas as causas para o aumento de casos: a disponibilidade de métodos diagnósticos mais sensíveis e precisos; a maior sensibilidade da vigilância epidemiológica que detecta mais casos e, consequentemente, aumentam as notificações; nova cepa mais virulenta e resistente aos antibióticos; redução da imunização após alguns anos da última dose de vacinação, o que pode levar à contaminação assintomática nos adultos, podendo contaminar as crianças que terão maior chance de possuir um quadro sintomático devido ao baixo sistema imunológico a elas conferido.

Dessa forma, propõe-se que, para a redução do número de casos e um maior controle da enfermidade, deve-se aumentar a quantidade de vacinas disponibilizadas pelo ministério da saúde, fortalecendo a homogeneidade no Brasil a fim de atender à demanda da população; reforçar os estados brasileiros a aderirem ao método diagnóstico por biologia molecular para que haja um diagnóstico precoce e, assim, oferecer um tratamento eficaz contra a coqueluche.

\section{Referências}

BARBOSA, M. C. L. et al. Efeitos da descentralização das ações de vigilância epidemiológica para as equipes de Saúde da Família. Revista Epidemiologia e Serviços de Saúde, Brasília, v. 19, n. 4, p. 347-354, dez. 2010. 
BRASIL. Centro de Vigilância Epidemiológica da Secretaria de Estado da Saúde de São Paulo. Manual de vigilância epidemiológica da coqueluche: normas e instrução. São Paulo: Governo de São Paulo, 2001.

BRASIL. Ministério da Saúde. Secretaria de Vigilância em Saúde. Departamento de Vigilância Epidemiológica. Guia de vigilância epidemiológica. 7. ed. Brasília: Ministério da Saúde, 2009.

BRASIL. Ministério da Saúde. Secretaria de Vigilância em Saúde. Departamento de Vigilância Epidemiológica. Doenças infecciosas e parasitárias: guia de bolso. 8 . ed. rev. Brasília: Ministério da Saúde, 2010.

BRASIL. Ministério da Saúde. Divisão de Doenças de Transmissão Respiratória. Secretária de Estado da Saúde. Situação epidemiológica da coqueluche: cenário global. São Paulo: Governo de São Paulo, 2011.

BRASIL. Ministério da Saúde. Superintendência de Vigilância em Saúde. Secretaria de Estado da Saúde. Gerência de imunizações e rede de frio. Goiás: Governo de Goiás, 2014a.

BRASIL. Ministério da Saúde. Calendário nacional de vacinação. Brasília: Ministério da Saúde, 2014b.

BRASIL. Ministério da Saúde. Prevenção: Ministério da Saúde incorpora vacina tríplice ao calendário das gestantes. Brasília: Ministério da Saúde, 2014c.

BRASIL. Diretoria de Vigilância Epidemiológica. Secretária de Estado da Saúde. Informe técnico coqueluche. Santa Catarina: Governo de Santa Catarina, 2014d.

BRASIL. Secretária de Estado da Saúde. Informe técnico: vacina difteria, tétano e coqueluche (dTpa). Brasília: Centro de Vigilância Epidemiológica, 2014e.

BRASIL. Ministério da Saúde. Coqueluche. Disponível em: <http://portalsaude.saude.gov.br/index.php/oministerio/principal/secretarias/svs/coqueluche $>$. Acesso em: 10 set. 2015 a.

BRASIL. Ministério da saúde. Sistema de Informação do Programa Nacional de Imunizações. Disponível em: $<$ http://pni.datasus.gov.br/apresentacao.asp $>$. Acesso em: 17 nov. 2015 b.

BRASIL. Departamento de Informática do Sistema Único de Saúde (DATASUS). Coqueluche: casos confirmados notificados no sistema de informação de agravos de notificação. Disponível em: <http://tabnet.datasus.gov.br/cgi/ deftohtm.exe? sinannet/cnv/coquebr.def $>$. Acesso em: 10 out. 2015 c.
BRASIL. Instituto Brasileiro de Geografia e Estatística (IBGE). Projeção da população do Brasil e das Unidades da Federação. Disponível em: <http://www.ibge. gov.br/apps/populacap/projecao/indez.html>. Acesso em: 28 abr. 2016a.

BRASIL. Instituto Brasileiro de Geografia e Estatística (IBGE). Aspectos demográficos: informações gerais. Disponível em: <http://www.ibge.gov.br/home/estatistica/ populacao/condicaodevida/indicadoresminimos/tabela1.shtm>. Acesso em: 10 maio 2016b.

BRASIL. Instituto Brasileiro de Geografia e Estatística (IBGE). Área territorial brasileira. Disponível em: $<$ http://www.ibge.gov.br/home/geociencias/areaterritorial/principal.shtm>. Acesso em: 9 maio 2016c.

BRASIL. Instituto Nacional de Meteorologia (INMET). Tempo. Disponível em: <http://www.inmet.gov.br/portal/index.php? $r=$ home2/page\&page $=$ tempo $>$. Acesso em: 10 maio $2016 \mathrm{~d}$.

BRASIL. Ministério da Saúde. Secretária de Vigilância em Saúde. Programa Nacional de Imunizações: 30 anos. Disponível em: <http://bvsms.saude.gov.br/bvs/ publicacoes/livro_30_anos_pni.pdf>. Acesso em: 10 jun. 2016 e.

BRASIL. Governo de Santa Catarina. Diretoria de Vigilância Epidemiológica. Informe técnico da vigilância da coqueluche em dezembro de 2015. Disponível em: <http://www.dive.sc.gov.br/conteudos/imunizacao/publicacoes/informe-tecnico-coqueluche-2015.pdf >. Acesso em: 15 jun. $2016 f$.

CARVAlHO, A. P.; PEREIRA, E. M. C. Acellular pertussis vaccine for adolescents. Jornal de Pediatria, Rio de Janeiro, v. 82, n. 3, suppl. 0, p. S15-S24, jul. 2006.

CARVALHO, L. H. F. R.; HIDALGO, N. T. R. Coqueluche. In: VERONESI, R.; FOCCACIA, R. Tratado de infectologia. 2. ed. São Paulo: Atheneu, 2002. v. 1. p. 625-633.

CENTRO DE BACTERIOLOGIA. Manual de diagnóstico laboratorial coqueluche. São Paulo: Instituto Adolfo Lutz, 2010.

KASSOUF, A. L. Acesso aos serviços de saúde nas áreas urbana e rural do Brasil. Revista de Economia e Sociologia Rural, Brasília, v. 43, n. 1, p. 29-44, jan./mar. 2005.

KONEMAN, E. W. et al. Diagnóstico microbiológico: texto e atlas colorido. 6. ed. Rio de Janeiro: Guanabara Koogan, 2012.

LONGO, D. L.; et al. Manual de medicina de Harrison. 8. ed. Porto Alegre: Artmed, 2013. 
MATTOO, S.; CHERRY, J. D. Molecular pathogenesis, epidemiology, and clinical manifestations of respiratory infections due to Bordetella pertussis and other Bordetella subspecies. Clinical Microbiology Reviews, Washington, v. 18, n. 2, p. 326-382, abr. 2005.

MOTTA, F.; CUNHA, J. Coqueluche: revisão atual de uma antiga doença. Boletim Cientifico de Pediatria, Rio Grande do Sul, v. 1, n. 2, p. 42-46, dez. 2012.

PASTOR, S. O. R.; MARTÍN, F. J. G.; MANSO, G. M. Eritromicina y estenosishipertrófica del piloro. Anales Españoles de Pediatria, Barcelona, v. 54, n. 3, p. 318, abr. 2013.

PINTO, L. A. M. Imunização nos primeiros anos de vida: as vacinas do programa nacional de imunização. Revista Hospital Universitário Pedro Ernesto, Rio de Janeiro, v. 6, n. 1, p. 19-33, jan./jun. 2007.

SBIM. Sociedade Brasileira de Imunização. Vacina tríplice bacteriana de células inteiras combinada com Hib e hepatite B (DTPw-HB/Hib). Disponível em: $\quad<$ http://familia.sbim.org.br/vacinas/vacinas-disponiveis/59-vacina-pentavalente $>$. Acesso em: 20 mar. 2016.
TORRES, R. S. L. A. et al. Ressurgimento da coqueluche na era vacinal: aspectos clínicos, epidemiológicos e moleculares. Jornal de Pediatria, Porto Alegre, v. 91, n. 4, p. 333-338, jul./ago. 2015.

TORTORA, J.; FUNKE, R.; CASE, L. Microbiologia. 10. ed. Porto Alegre: Artmed, 2012.

TOZZI, A. E. et al. Diagnosis and management of pertussis. Canadian Medical Association Journal, Ottawa, v. 172, n. 4, p. 509-515, fev. 2005.

ULLOA, F. M. T. Bordetella pertussis. Revista Chilena de Infectologia, Santiago, v. 25, n. 2, p. 115, abr. 2008.

VIEIRA, E. W. R. Acesso e utilização dos serviços de saúde de atenção primária em população rural do município de Jequitinhonha, Minas Gerais. 2010. 125 f. Dissertação (Mestrado) - Escola de Enfermagem, Universidade Federal de Minas Gerais, Belo Horizonte, 2010.

WILLEMANN, M. C. A. et al. Adoecimento por coqueluche e número de doses administradas de vacinas Pertussis: estudo de caso-controle. Epidemiologia e Serviços de Saúde, Brasília, v. 23, n. 2, p. 207-214, abr./ jun. 2014. 